\title{
A Review on Diabetes Mellitus: Current Update on Management and Treatment
}

\author{
Gopala Krishna Chinnaboina ${ }^{1,2}$, AMS SudhakarBabu ${ }^{2}$, Rajesh Verma ${ }^{1}$, Pankaj Sharma ${ }^{1}$, \\ BirendraShrivastava ${ }^{1}$ \\ ${ }^{I}$ School of Pharmaceutical Sciences, Jaipur National University, Jagatpura-302017, Jaipur, India \\ ${ }^{2}$ AM Reddy Memorial College of Pharmacy, Narasaraopet, Guntur, India
}

Received: 25-06-2018 / Revised: 02-07-2018 / Accepted: 27-07-2018

\begin{abstract}
Diabetes mellitus (DM), or simply diabetes, is a group of metabolic diseases in which a person has high blood sugar, either because the body does not produce enough insulin, or because cells do not respond to the insulin that is produced. This high blood sugar produces the classical symptoms of polyuria (frequent urination), polydipsia (increased thirst) and polyphagia (increased hunger). Conventionally, diabetes has been divided into three types namely: Type $1 \mathrm{DM}$ or insulin-dependent diabetes mellitus (IDDM) in which body fails to produce insulin, and presently requires the person to inject insulin or wear an insulin pump. This is also termed as "juvenile diabetes". Type 2 DM or non-insulin-dependent diabetes mellitus (NIDDM), results from insulin resistance, a condition in which cells fail to use insulin properly, with or without an absolute insulin deficiency. This type was previously referred to as or "adult-onset diabetes". The third main type is gestational diabetes which occurs when women without a previous history of diabetes develop a high blood glucose level during her pregnancy. It may precede development of type 2 DM. Currently available pharmacotherapy for the treatment of diabetes mellitus includes insulin and oral hypoglycemic agents. Such drugs acts by either increasing the secretion of insulin from pancreas or reducing plasma glucose concentrations by increasing glucose uptake and decreasing gluconeogenesis. However these current drugs do not restore normal glucose homeostasis for longer period and they are not free from side effects such as hypoglycemia, kidney diseases, GIT problems, hepatotoxicity, heart risk problems, insulinoma and they have to take rest of life. Various herbal drugs have been also proved effective due to their beneficial contents in treatment of diabetes. The present review therefore is an attempt to focus on the physiological aspects of diabetes, its complications, goals of management, and synthetic and herbal treatment of diabetes.
\end{abstract}

Key words:Insulinoma, hyperinsulinemia, adiponectin, Momordicacharantia.

\section{Introduction}

Diabetes mellitus is a metabolic disorder initially characterized by a loss of glucose homeostasis with disturbances of carbohydrate, fat and protein metabolism resulting from defects in insulin secretion, insulin action, or both. Without enough insulin, the cells of the body cannot absorb sufficient glucose from the blood; hence blood glucose levels increase, which is termed as hyperglycemia. If the glucose level in the blood remains high over a long period of time, this can result in long-term damage to organs, such as the

*Correspondence

Gopala Krishna Chinnaboina

AM Reddy Memorial College of Pharmacy, Narasaraopet, Guntur, India.

E-Mail: gopipharma.ch@gmail.com kidneys, liver, eyes, nerves, heart and blood vessels. Complications in some of these organs can lead to death. Diabetes Mellitus is a constitutional disease. It is also known as "Disease of Civilization" (Urbanization) seen more in cities than villages. But however it is now making inroads into Indian villages. Diabetes is an important human ailment afflicting many from various walks of life in different countries. It is an outcome of sedentary life style \& incorrect food habits. No. of people afflicted by Diabetes Mellitus is increasing each day. 9-12\% population of world has either established Diabetes Mellitus (or) tendency of contracting it in near future.18 Millions of Indians are suffering from Diabetes Mellitus. Though it is rampant today, it is not a new disease. It is wellknown from historic times. Well known ayurvedic 
physicians MaharshiCharaka(600BC) \&Sushrutha (400BC) correctly described almost all the symptoms of this disease and called it as "MadhuMeha"(a shower of honey) and explained in ayurvedic literature called 'SushruthaSamhitha'[1-6]After the discovery of insulin, people had started believing that Diabetes Mellitus will soon be banished from the earth. However this belief has turned out to be a dream \& proved fallacious. With vigorous treatment, shortterm complications of Diabetes Mellitus can be checked; but its long-term complications can be hardly being prevented. Diabetes is one of the oldest known diseases. An Egyptian manuscript from c. 1550 BCE mentions the phrase "the passing of too much urine". The great Indian physician Sushruta identified the disease and classified it as Medhumeha: The ancient Indians tested for diabetes by observing whether ants were attracted to a person's urine, and called the ailment "sweet urine disease" (Madhumeha)[7-10].

Concerning the sweetness of urine, it is to be noted that the Chinese, Japanese and Korean words for diabetes are based on the same ideographs which mean "sugar urine disease". It was in 1776 that Matthew Dobson confirmed that the sweet taste comes from an excess of a kind of sugar in the urine and blood. The first complete clinical description of diabetes was given by the Ancient Greek physician Aretaeus of Cappadocia (fl. 1st century CE), who noted the excessive amount of urine which passed through the kidneys and gave the disease the name "diabetes."Diabetes mellitus appears to have been a death sentence in the ancient era. Hippocrates makes no mention of it, which may indicate that he felt the disease was incurable. In medieval Persia, Avicenna (980-1037) provided a detailed account on diabetes mellitus in The Canon of Medicine, "describing the abnormal appetite and the collapse of sexual functions," and he documented the sweet taste of diabetic urine. Avicenna recognized a primary and secondary diabetes. He also described diabetic gangrene, and treated diabetes using a mixture of lupine, trigonella (fenugreek), and zedoary seed, which produces a considerable reduction in the excretion of sugar, a treatment which is still prescribed in modern times. Avicenna also "described diabetes insipidus very precisely for the first time", though it was later Johann Peter Frank (1745-1821) who first differentiated between diabetes mellitus and diabetes insipidu.[5,6,11-13]

Although diabetes has been recognized since antiquity, and treatments of various efficacy have been known in various regions since the Middle Ages, and in legend for much longer, pathogenesis of diabetes has only been understood experimentally since about 1900 In 1910, Sir Edward Albert Sharpey-Schafer suggested that people with diabetes were deficient in a single chemical that was normally produced by the pancreas; he proposed calling this substance insulin, from the Latin insula, meaning island, in reference to the insulin-producing islets of Langerhans in the pancreas.Insulin production and therapy rapidly spread around the world, largely as a result of this decision. Banting is honored by World Diabetes Day which is held on his birthday, November14.The distinction between what is now known as type 1 diabetes and type 2 diabetes was first clearly made by Sir Harold Percival (Harry) Himsworth, and published in January 1936.Despite the availability of treatment, diabetes has remained a major cause of death. For instance, statistics reveal that the cause-specific mortality rate during 1927 amounted to about 47.7 per 100,000 population in Malta.[3,4,14-17]

\section{Epidemiology of diabetes mellitus}

The prevalence of diabetes mellitus is increasing with ageing of the population and lifestyle changes associated with rapid urbanization and westernization. The disease is found in all parts of the world and is rapidly increasing in its coverage [18-20].

\section{Prevalence and incidence of diabetes mellitus}

Globally, the prevalence of diabetes without type distinction, was estimated to be $4 \%$ in 1995 . According to WHO, it is estimated that $3 \%$ of the world's population have diabetes and the prevalence is expected to double by the year 2025 to $6.3 \%$. There will be a $42 \%$ increase from 51 to 72 million in the developed countries and $170 \%$ increase from 84 to 228 million, in the developing countries. Thus, by the year 2025 , over $75 \%$ of all people with diabetes will be in the developing countries, as compared to 62\% in 1995. The reasons behind this projected increase in prevalence rate are due to urbanization, westernization and their associated lifestyle changes, increase in life expectancy at birth, physical inactivity and obesity and possibly a genetic predisposition. Age, ethnic, regional and racial differences have also been found to play a role for the diabetic incidence in heterogeneous populations within the same area [21-23].

\section{Types of Diabetes Mellitus}

Diabetes results in the impairment of the body's ability to use food because either the pancreas does not make insulin or the body cannot use insulin properly. Hypoglycemia (low blood glucose) is most commonly seen in diabetic patients, when the body gets too much 
insulin, too little food, a delayed meal, or more than the usual amount of exercise. When the body gets too little insulin, too much food, or too little exercise, it results in hyperglycemia (high blood glucose). Stress may contribute to hyperglycemia. Hyperglycemic state (diabetes mellitus) arises when the blood glucose (sugar) levels are higher than $180 \mathrm{mg} / \mathrm{dl}(10 \mathrm{mmol} / \mathrm{l})$. Diabetes is of mainly three types. They are type-1 diabetes (T1D), type-2 diabetes (T2D) and gestational diabetes mellitus. T1D, also called as the insulindependent diabetes mellitus (IDDM), manifests due to the autoimmune damage of the $\beta$-cells which then leads to the suppression or cessation of insulin production. T1D is also called the "juvenile diabetes". T2D, also called as the adult-onset diabetes or non-insulindependent diabetes mellitus (NIDDM) among humans is caused by either low levels or absence of insulin or insulin resistance (IR). Gestational diabetes mellitus (GDM) is defined as glucose intolerance of varying degrees, which appears, or is first diagnosed, during pregnancy and may or may not persist after delivery. The type 1 diabetes mellitus (T1DM) is a multifactorial autoimmune disease characterized by chronic hyperglycemia and by the development of specific vascular alterations. Autoimmune destruction of $\beta$-cell by T-cells, is responsible for T1DM which results in severe insulin depletion. It is also known as juvenile diabetes.

Type 2 diabetes mellitus (T2DM) is a chronic disease characterized by insulin resistance, which leads to hyperglycemia. More than 180 million people worldwide have diabetes as estimated by The World Health Organization (WHO). T2DM is expected to reach pandemic levels, rising from 171 million in 2000 to 366 million in 2030. T2DM is the more prevalent form and accounts $90 \%$ of all diabetes cases worldwide. The key features of type 2 diabetes is insulin resistance associated with obesity due to the release of free fatty acids (FFA) and the release of inflammatory cytokines from the expanded adipose tissue mass. The decreased ability of insulin to regulate glucose metabolism is known as insulin resistance. Intracellular lipid accumulation occurs due to increased import of FFA into nonadipose tissues. Ragheb R et al. reported that disturbances of lipids in the body lead to development of insulin resistance and metabolic diseases [24-28].

Gestational Diabetes Mellitus (GDM) occurs in approximately $7 \%$ of pregnancies and there is a greater risk of morbidity and mortality to mother, fetus and subsequent neonate. Intensive monitoring and treatment is necessary for GDM. Women with the history of gestational diabetes mellitus (GDM) have a significantly increased risk of type 2 diabetes and of cardiovascular disease during the next years after delivery [23-32].

\section{Factors Causing Diabetes}

T1DM is mainly triggered by environmental factors. The main factors that contribute to the development of insulin resistance (T2DM) include obesity, physical inactivity, and smoking. The prevalence of diabetes mellitus is increasing due to urbanisation, westernisation and their associated lifestyle changes (nutritional habits, lack of adequate dietary intake and low physical activity) accompanied by obesity, and low socioeconomic level. Body weight is one of the most important modifiable risk factors in T2DM. Obesity is an independent risk factor for dyslipidaemia, hypertension and cardiovascular disease and increases the risk of cardiovascular complications and mortality in patients with T2DM. Age is another factor that is associated with T2DM. The pancreas of an aged person doesn't pump insulin as efficiently as it did in younger ones. High blood pressure and high cholesterol also contribute to T2DM.

Mutations in insulin gene and insulin receptors also contribute to type 2 diabetes. Sphingosine-1-phosphate (S1P) is an important bioactive phospholipid with a wide range of cellular functions. In individuals with T2D, S1PR2 was shown to be down-regulated in platelets. S1PR2 variant $\mathrm{Val} \rightarrow$ Ala at position 286 associated significantly with the incidence of diabetes. Novel Val $\rightarrow$ Ala polymorphism at position 286 in the NPXXY motif of S1PR2 is significantly associated with incidence and age at onset of diabetes in the LURIC study cohort. Hepatic insulin sensitivity in young human subjects tends to be reduced with TCF7L2 (Transcription factor 7-like 2) gene polymorphism whereas peripheral increased insulin sensitivity is observed in older human individuals. It is very difficult to map genes related to T2DM in humans, because environmental factors such as dietary intake and life style, influence the genetic effects of T2DM. The hepatocyte nuclear factor 4- $\alpha$ (HNF4 $\alpha$ ) gene codes for a transcription factor which is responsible for regulating gene transcription in pancreatic beta cells. HNF4 $\alpha$ has also been associated with the regulation of glucose transport and metabolism. Disruptions in this gene can lead to (MODY), an autosomal dominant, non-insulin dependent form of diabetes known as maturity onset diabetes of the young (MODY)[33-36].

\section{Complications}

Diabetes is root cause for several serious complications such as cardiovascular diseases, cerebrovascular diseases, renal disorders, inflammation and immunity, 
and obesity. Epidemiological studies of diabetes mellitus have shown that gender, age, and ethnic background are important factors when considering the development of diabetes mellitus and its complications. Amadori glucose adducts modifies albumin into glycated albumin, which is associated independently with diabetes complictions. The diabetes complications are equally associated with the both types of DM. Defects in insulin metabolism and dysfunction in carbohydrate, lipid and protein metabolism leads to high blood levels of glucose which results in long-term complications. Diabetic complications include hypertension, retinopathy, end-stage renal disease, neuropathy, peripheral vascular disease, electrolyte imbalance, immune suppression, erectile dysfunction, and complications of pregnancy.

Diabetes leads to increased levels of endothelial micro particles. Diabetic ketoacidosis (DKA) is a serious condition caused by hyperglycemia, if the patient is not treated over a period of days. It is characterized by nausea, vomiting, and a high level of ketones in the blood and urine. Addison's disease, Grave's hyperthyroidism, hypothyroidism, hypogonadism, coeliac disease, pernicious anaemia and vitiligo are some of the autoimmune disorders associated with diabetes. Keratoconus is a non-inflammatory corneal disease seen in some diabetic patients. Hypoglycemia causes insulinoma, an islet beta cell-derived tumor manifesting various clinical symptoms. Insulinoma is diagnosed by the measurement of proinsulin.

Decreased number of pump units on the erythrocyte membrane, altered lipid - protein interaction, depleted membrane anionic charge and enzyme glycation and peroxidation contribute to many abnormal complications in Diabetes mellitus. Na+K+-ATPase a membrane bound enzyme that energizes the Napump by hydrolyzing ATP is associated with action of insulin. Lack of insulin decreases $\mathrm{Na}+\mathrm{K}+$-ATPase activity which can cause obesity- one of the major causes for type2 diabetes mellitus.[37-40]

Secondary carnitine deficiency is commonly seen in T1DM. Most of the disorders of fatty acid metabolism are associated with abnormal carnitine or acylcarnitine levels and recurrent hypoglycemia. Medium chain acyl-CoA dehydrogenase deficiency (MCADD) is the most common among them occurs during a prolonged fast or during acute illness. A significant reduction in HbA1c was seen in patients with carnitine deficiency. MODY is an autosomal dominant single gene hereditary disease and account for about $2 \%-5 \%$ of type 2 diabetes. It usually appears before the age of 25 and occurs mostly in children and adolescents, characterized by $\beta$ cell disfunction. Isoleucine, citrate, inositol, 1-methylhistidine and tyrosine are the differential metabolites considered biomarkers for predicting probable MODY.Western life style nutrition is associated with increased insulin/IGF-1 signaling that results in acne formation. Endocrine disorders with increased levels of insulin and/or IGF-1 and insulin resistance are often associated with acne like HAIRAN (hyperandrogenism, insulin resistance, acanthosisnigricans) syndrome. It is clearly evident that in many cases of psoriasis, diabetes is a major comorbidity along with hypertension. Several systemic diseases associated with syringomas (tumours) were reported in patients with diabetes mellitus[41-43].

\section{Diabetic retinopathy}

Diabetic retinopathy (DR) is damage to the eye's retina that occurs with long-term diabetes. Diabetic retinopathy is is the most common cause of blindness in most of the countries. It is commonly seen in both type $1(40 \%)$ and type 2 DM (20\%). There are two types of diabetic retinopathy. They are Nonproliferative which develops first, Proliferative is the more advanced and severe form of the disease. In patients with T2DM involvement of fovea by edema and hard exudates or ischemia is the most common cause of visual impairment. Hyperglycemia and the increased duration of diabetes are the major risk factors for DR. Other risk factors include hypertension, hyperlipidemia, pregnancy, and microalbuminuria. Symptoms of diabetic retinopathy appears only after the damage occurs to eyes which include- Blurred vision and slow vision loss over time, floaters, Shadows or missing areas of vision, trouble seeing at night. The vascular commitment is the most serious and common condition in DM. The factors for vascular damage of DM include poor glycemic control, lipoprotein abnormalities, hypertension, oxidative stress (OS), inflammation and advanced glycation endproducts (AGEs). Retinopathy is characterized by increased vascular permeability, by vascular closure mediated by the formation of new blood vesselsneovascularization, on the retina and posterior surface of the vitreous. Generally, neovascularization results from occlusion of fragile capillaries and frequently originate pre-retinal and vitreous hemorrhage in case of vitreous detachment. Much attention has been focused on the role of OS in the pathogenesis of diabetic complications is of much importance. The retina is highly susceptible to OS and the oxidation products are toxic to the microvascular walls and therefore results in diabetic microvascular damage. Diagnosis of retinopathy is based on finding the diagnostic signs of retinopathy on eye exams by fundoscopy[44-46]. 


\section{Diabetic maculopathy}

Diabetic maculopathy is most commonly seen in T2DM whereas macular ischemia is more frequently seen in T1DM. Diabetic maculopathy consist of macular edema and ischemia[44,47].

\section{Macular ischemia}

Macular ischemia is a devastating condition that causes irreversible visual loss. It is seen mostly in T1DM. Basement membrane thickening, increased viscosity of blood and endothelial cell damage occurs in the pathogenesis of macular ischemia[48-50].

\section{Diabetic macular edema}

Diabetic macular edema is the leading cause of visual loss in patients with non proliferative diabetic retinopathy. DME is the consequence of accumulation of fluid in the retina after dysfunction of the blood retinal barrier. Breakdown in blood retinal barrier at the level of the perifoveal vessels results in edema[51,52].

\section{Cataract}

Cataract develops at an earlier age in diabetic patients which is characterized by clouding of the eye lens. In cataract the lens becomes opaque, reducing the amount of light reaching the retina. Connexins $(\mathrm{Cx})$ are a family of proteins that forms hemichannels that communicate the cytoplasm with the extracellular space. Under oxidative stress conditions such as diabetes, it is possible that $\mathrm{Cx}$ oxidation may contribute to cataract formation. Neurotrophic corneal ulcers may develop in patients with DM[53-55].

\section{Glaucoma}

Glaucoma is a condition in which increase in fluid pressure inside the eye leads to optic nerve damage and loss of vision. A person with diabetes is more prone to get glaucoma compared to others[56,57].

\section{Cardiovascular diseases associated with diabetes}

Cardiovascular disease is the leading cause of morbidity and mortality in patients with diabetes mellitus. Patients with diabetes mellitus have a 2 to 4 times higher risk of cardiovascular disease and up to a 3 times increase in mortality than non diabetics. Increased body mass index, diabetes, hypercholesterolemia, smoking, male-sex, family history and age are the risk factors for coronary heart disease and atherosclerosis. Increased pulse pressure causes stiffening of arteries which is an independent risk factor for cardiovascular diseases. Use of LXRalpha ligands may be beneficial for the treatment of diabetes induced Coronary Artery Disease. Some studies confirmed that the risk factor burden tended to be higher among women, with a greater prevalence of obesity and trends toward higher rates of hypertension, diabetes mellitus and home stress. Atherosclerosis, coronary artery disease myocardial infarction are the commonly associated cardiovascular diseases in diabetic patients. Individuals with T2DM are at higher risk of cardiovascular diseases (CVD) than those without T2DM. Diabetes, dyslipidemia, hypertension and obesity are well-known major and independent cardiovascular risk factors. Diabetes mellitus is also a strong and independent risk factor for congestive heart failure. Disturbed conductibility of the left ventricle $(\mathrm{LV})$ is the characteristic feature of this common complication. Hyperosmolarity is a condition of higher osmolarity commonly seen in diabetic patients. Hong Chen et al. reported that cardiovascular eNOS, HO and HSP90 were induced by hyperosmolarity in DM. The heart rate and blood pressure is generally altered in response to changes in arterial wall tension detected by the arterial baroreceptors in the carotid sinus and aortic arch by a mechanism known as Arterial baroreflex. Endogenous Ang II-NADPH oxidase-superoxide signaling is over-activated in the nodose ganglia, which contributes to the attenuated arterial baroreflex function in the diabetes. Cardiovascular disease, particularly coronary artery disease, is a major cause of morbidity and mortality among patients with diabetes mellitus. Atrial Fibrillation (AF) is associated with diabetes due to increased oxidant stress. Shock therapy is used for supra ventricular arrhythmias including atrial fibrillation (AF), atrial flutter, etc. There is also evidence that hyperglycemia may induce diabetic angiopathy through the generation of OS or through the accumulation of AGEs, leading to nitrous oxide systems (NOS) [58-62].

Atherosclerosis is characterized by chronic inflammation affecting the arterial intima. Low plasma HDL cholesterol (HDL-C) is consistently associated with increased risk of atherosclerotic disease [63].

Diabetes patients have low levels or impaired HDL (High density lipid protein) metabolism. The increased pulse pressure (PP) was an effect of the atherosclerotic disease. Hyperinsulinemia, a major feature of T2DM and the meta $\neg$ bolic syndrome, is believed to be highly associated with the occurrence of atherosclerosis and vascular restenosis. Increased neointima formation caused by vascular injury via potentiating smooth muscle cell migration and pro $\neg$ liferation is commonly seen in patients with hyperinsulinemia. The application of insulin sensitizers, such as synthetic thiazolidinediones (STD), significantly reduces carotid artery intima/ media thickness in patients with T2DM [64-67].Left ventricular (LV) hypertrophy is a potent independent risk factor for cardiovascular morbidity and mortality caused due to hypertension and obesity. The association between LV hypertrophy and impaired glucose tolerance was described by several 
epidemiological studies. Increased LV mass is a main risk factor for cardiac events such as myocardial infarction and heart failure. Previously it was described in many studies that the association between DM and cardiac abnormalities is more evident in women than men. Alexander Riad et al. showed that this association is equal in both women and men $[68,69]$. Obesity is associated with an increase risk for cardiometabolic diseases such as atherosclerosis and T2DM. Oxidative stress results of an imbalance between the production and degradation of reactive oxygen species such as hydrogen peroxide (H2O2). Glutathione peroxidase (GPx) regulates the concentration of $\mathrm{H} 2 \mathrm{O} 2$. A modification in GPx levels affects directly the intracellular level of peroxides; a slow-down of its activity allows higher intracellular concentration of peroxides whereas a stimulation of GPx activity leads to lower $\mathrm{H} 2 \mathrm{O} 2$ concentration. High GPx activity is associated with numerous potentially clinically relevant cardiometabolic abnormalities [70-72].

\section{Macro-and microvascular complications}

Macro-and microvascular complications are mostly seen in diabetic patients. Macrovascular disease includes coronary heart disease (CHD), cerebrovascular disease, and peripheral vascular disease. It is the leading cause of mortality in people with diabetes. Microvascular complications include effects on small vessels, including arterioles, capillaries and venules. Diabetes-related microvascular complications are rare in childhood and adolescence. Platelets play a key role in the microvascular as well as macrovascular complications of diabetic patients. Hyperglycemia changes platelet functions by impairing calcium homeostasis. Lower fetuinA levels were found in Patients with diabetes. Fetuin $\mathrm{A}$ is a circulating calcium-regulatory glycoprotein that inhibits ectopic and vascular calcification. Aortic stenosis (AS) is a disease process involving an active calcification of the aortic valve (AV). Chronic hyperglycemia is mainly involved in the pathophysiology of microangiopathy and it is the main cause for diabetes microvascular complications. Microalbuminuria, a precursor of diabetic nephropathy is associated with a generalized endothelial vascular dysfunction. Early diabetes is often accompanied by an increased glomerular filtration rate (GFR) and hyperfiltration which is significantly dependent upon increased NO activity and contributes to progression of diabetic nephropathy. Serum and urinary NO levels were found to be significantly increased in diabetics compared to normal individuals [73-75].

Diabetic nephropathy
Diabetic nephropathy is kidney disease or damage that occurs in people with diabetes. Diabetic nephropathy is one of the most important causes $(61 \%)$ of endstage renal disease that requires renal replacement therapy. In people with diabetes, the nephrons thicken and slowly become scarred over time. The kidneys begin to leak and protein (albumin) passes into the urine. People who have more severe kidney disease may have a poor appetite, feel tired most of the time, and have a general ill feeling. Headache, nausea and vomiting, swelling of the legs, and many other symptoms may also occur. Clinical progression to diabetic nephropathy is not apparently seen in T2DM as it is in T1DM, because of the difficulty in determining the acute onset of diabetes itself. Sometimes it is difficult to differentiate minimal change nephritic syndrome (MCNS) and membranous nephropathy (MN) from diabetic nephropathy, especially in middle to advanced aged patients with T2DM because it does not cause hematuria. Diabetic nephropathy was the leading cause of end stage renal disease (ESRD) $(61 \%)$ in patients with Intradialytic hypotension (IDH) [76-78].

\section{Diabetic neuropathy}

Diabetes mellitus, a common metabolic disease with a rising global prevalence, is associated with long-term complications of peripheral nervous system and the central nervous system. Diabetic neuropathy is a common complication of diabetes that results in damage to the nerves due to high blood sugar levels for a long period of time. There are four types of diabetic neuropathy- peripheral, autonomic, proximal, and focal. Symptoms of nerve damage include numbness, tingling, or pain in the toes, feet, legs, hands, arms, and fingers, wasting of the muscles of the feet or hands, indigestion, nausea, or vomiting, diarrhea or constipation, dizziness or faintness due to a drop in blood pressure after standing or sitting up, problems with urination, erectile dysfunction in men or vaginal dryness in women, weakness [79,80].

Stroke is the leading cause of death and disability worldwide. Common risk factors for stroke were documented including high blood pressure, diabetes, previous stroke and myocardial infarction, cardiovascular disease, hyperlipidaemia, atrial fibrillation, periphery artery occlusive disease (PAOD), current smoking and alcohol consumption. Spontaneous intracerebral hemorrhage (sICH), defined as spontaneous bleeding into the brain, accounts for $10 \%$ to $20 \%$ of all strokes is associated with diabetes $(81,82)$.

Diabetic encephalopathy is also called as encephalopathy or malfunction of brain. The complications include impaired spatial cognitive 
functions, memory loss, dementia, coma, seizures and death. It involves direct neuronal damage caused by intracellular glucose. It is a poor coordination of brain, which affects the movements of limbs [83,84].

\section{Osteoporosis and osteoarthritis}

Diabetes is a higher risk factor for bone and joint disorders. Osteoporosis is a thinning of the bones that weakens them and increases the risk of fractures. Osteoarthritis is a joint disorder caused by the degeneration of the joint cartilage between bone resulting in joint pain, swelling and stiffness. Individuals diagnosed with T1DM are at an increased risk of developing osteoporosis, while those with T2DM are at an increased risk of osteoarthritis. Incidence of osteoporosis and T2DM is known to increase in prevalence with aging. Ducy and Karsenty's group showed that the expression of insulin in pancreatic $\beta$ cells as well as of adiponectin in adipocytes is increased by osteocalcin. Recent studies have identified osteopathy as a serious complication of type 1 and type 2 diabetes. Disruption of insulin and insulin-like growth factor 1 (IGF-1) homeostasis in the diabetic condition may be responsible for the observed skeletal deficits. T2D is not associated with osteopenia or osteoporosis, but recent studies have reported that subperiosteal porosity is increased in T2D patients who fracture. It has been recognized that the alterations in mineral and bone metabolism were associated with DM and that the resulting bone loss is one of the chronic complications of diabetic patients. Both type 1 and type 2 diabetes are associated with changes in the bone mineral density (BMD) and bone turnover markers. Bone mineral density (BMD) is reduced in T1D, whereas an increased BMD is seen in T2D. An increased risk of hip fractures is seen in both T1D and $\mathrm{T} 2 \mathrm{D}$, the increase in risk of fractures being more pronounced in T1D than in T2D. T2D is a risk factor for hip, proximal humerus, and foot fractures among older women. Arreola et al. showed a significant decrease in both bone mineral content and zinc, suggesting that zinc deficiency may be a contributory factor to bone loss in T1DM individuals with poor glycemic control. Hill et al. showed that zinc stimulates osteoblasts in adult's withT1DM[85-88].

\section{Diagnostic Methods of Diabetes}

Diabetes mellitus is diagnosed by demonstrating any one of the following methods:

Fasting plasma glucose level $\geq 7.0 \mathrm{mmol} / \mathrm{L} \quad(126$ $\mathrm{mg} / \mathrm{dL}$ )

Plasma glucose $\geq 11.1 \mathrm{mmol} / \mathrm{L}(200 \mathrm{mg} / \mathrm{dL})$

Glycated hemoglobin ( $\mathrm{Hb} \mathrm{A} 1 \mathrm{C}) \geq 6.5 \%$

Oral glucose tolerance test (OGTT)
People with fasting glucose levels from 100 to 125 $\mathrm{mg} / \mathrm{dL}$ are considered to have impaired fasting glucose also called as pre-diabetes. Fasting plasma glucose is mostly preferred because of its low cost and is very easy to operate. Diabetes should be confirmed with a second test on a different day. The 2-hour oral glucose tolerance test (OGTT) is a standard test for diagnosing type 2 diabetes but it is expensive and is limited because of its labor-intensive multi-blood draw protocols. Both the methods require patients to be tested in the fasted state. Glycatedhaemoglobin (HbA1c) requires only a single point blood draw and is more advantageous because it does not require fasting blood samples and has higher repeatability. HbA1c is an indicator of the average blood glucose concentration over the preceding three months and has been proposed to be a useful alternative test to screen for type 2diabetes as it overcomes many of the obstacles associated with the OGTT. Glycated hemoglobin is better than fasting glucose for determining risks of cardiovascular disease and death from any cause. HbAlc should be considered in the clinical setting because of the greater ease and lower cost of measurement. HbA1c has been suggested to be superior to FPG for the prediction of vascular disease and death from any cause among nondiabetic subjects. Latest methods for diagnosis include continuous monitoring of interstitial glucose (CGMS) and new proposed methods include seven-point self-monitored blood glucose (SMBG) profiles along with calculation of weekly mean blood glucose (WMG) and glycemic variability $(\mathrm{GV})$. A positive association between obesity and the risk of developing T2D has been consistently observed in many populations. Usual anthropometric parameters used to measure obesity are BMI (Body Mass Index), WC (Waist Circumference) \& WHR (Waist Hip Ratio). The most commonly used criteria to diagnose obesity are National Cholesterol Education Program (NCEP), ATP III criteria. According to sensitivity, Pandya et al. suggested WC as a better indicator than BMI for diabetes status. The American Diabetes Association suggests that sudomotor function assessing small fiber status should be included in the diagnostic tests for the detection of neuropathies in diabetes[89-92].

\section{Treatment}

The treatment for diabetes mainly involves the regulation of blood sugar levels and to prevent diabetic complications. Medicines, diet, and exercise are included in treatment. Lifestyle modifications and oral anti-diabetic medications are recommended for initial treatment of DM. 
Banting and Macleod first discovered the insulin hormone. Insulin therapy is required for T1D because cells cannot produce insulin. Although cells produce insulin harmone in type 2 diabetes but they donot respond normally to insulin. In such cases insulin therapy helps cells to overcome the resistance to insulin. Continuous subcutaneous insulin infusion (CSII) is useful therapy for brittle T1D worldwide. The frequency of hypoglycemia was decreased and improved glycemic variability was achieved with CSII therapy which is beneficial to pregnant women with diabetes[93-96].

\section{Insulin Types}

The most commonly-used human insulin preparations are Regular (rapid onset of action, short duration of action) and NPH (slower onset of action, longer duration of action). Regular insulin has an onset of action (begins to reduce blood sugar) within 30 minutes of injection, reaches a peak effect at 1-3 hours, and has effects that last 6-8 hours. NPH insulin is insulin with an intermediate duration of action. It has an onset of action starting about 2 hours following injection. It has a peak effect 4-12 hours after injection, and duration of action of 18-26 hours. Lente insulin also is insulin with an intermediate duration of action. It has an onset of action 2-4 hours after injection, a peak activity 6-12 hours after injection, and duration of action of 18 to 26 hours. Insulin lispro was developed by modification at the B26-30 regions of insulin. It was approved by the FDA in June, 1996. It was absorbed faster and had a shorter duration of action: action started within 15 mins of injection, peaked by an hour and disappeared within four hours. When lispro was modified to a protamine formulation of neutral protamine lispro, it gave similar overall glycemic control, with improved postprandial glucose. Insulin aspart was developed by substituting proline with aspartic acid. It has the advantage of reducing the selfassociation and enhancing the absorption rate. Insulin glargine was developed by elongating the $\mathrm{C}$ terminal of insulin B chain by two arginine residues: A21 aspargine residue was substituted with glycine. Insulin glargine has a slower onset of action (70 minutes) and a longer duration of action (24 hours) than regular human insulin. Its activity does not peak. Recent rapid acting insulin analogues include Insulin glulisine which is by derived from human insulin by the replcement of AspB3 by Lys and LysB29 by Glu. Both glulisine and lispro are absorbed faster than regular insulin and both displayed non-inferiority of glycemic control in all types of diabetes. Insulin analogues have so many advantages, but they are not used more extensively because they are more expensive than regular insulins[97,98].

Intensive glycaemic control in type 2 diabetes remarkably reduces the risk of development of microvascular complications proved by the United Kingdom Prospective Diabetes Study (UKPDS). Biphasic insulin aspart 30 (BIAsp 30) (NovoMixR30) is an insulin analogue mixture which contains $30 \%$ unbound rapid-acting insulin aspart and $70 \%$ intermediate-acting protaminated insulin aspart. IMPROVETM reported that Insulin initiation with BIAsp 30 is a safe and effective method of insulin therapy because it is improved without an increased risk of major hypoglycaemic conditions. ArushiSaini et al. study demonstrated that once-daily insulin glargine may be more efficacious than NPH insulin in the treatment of T1D [99,100]

Riddle et al. have reported that improved glycemic control accompanied by weight loss was achieved when pramlintide, an amylin analogue, was used in combination with insulin glargine. Davidson et al. found marked improvement in diabetes control in obese, severely insulin resistant T2D patients when U500 regular insulin substituted for U-100 NPH insulin. Allen Nichol et al. reported that by judicious use of these three drugs insulin glargine, U-500 insulin and pramlinitide, total number of drugs patient needed to control diabetes has been reduced from 5 to $3[34,101]$. Based on the insulin mechanism of action, various drugs have been developed, called insulin secretagogues, which stimulate beta cells of pancreas for a) secretion of additional insulin e.g. sulphonylureas and b) insulin sensitizers e.g. metformin. The sensitizers increases action of the existing insulin and facilitate greater uptake of glucose from plasma. Hence they are called insulin sensitizers. Insulin sensitization is commonly understood as glucose clearance from plasma without additional inputs of insulin. In contrast, insulin resistance is thought to be poor glucose clearance despite presence of high amounts of insulin. For insulin sensitization, metformin is a commonly used drug for treating T2D. Metformin was approved by FDA in December 1994. Fiber foods and gums such as fenugreek seeds are found to bring glycemic control in diabetic subjects. Fiber because of its viscosity reduces circulating insulin levels[102,103]

\section{Oral hypoglycemic agents}

Most widely used oral hypoglycemic agents include Sulfonylureas. Thiazolidinediones are widely used oral 
hypoglycemic agents which decrease glucose levels in type-2 diabetic patients by increasing the insulin sensitivity of target tissues. Metformin lowers blood glucose both by increasing insulin sensitivity and by decreasing hepatic gluconeogenesis. Metformin causes weight loss and a modest reduction in serum LDL cholesterol and triglyceride levels. Methadone is an opioid agonist which brings about its action by stimulation of $\mu$-receptors as well as antagonism of glutaminergic N-methyl-Daspartate (NMDA) receptors. Methadone has been used to manage chronic pain and also as an analgesic in diabetic neuropathy[104,105].

American Diabetes Association and The European Association for the Study of Diabetes recommended metformin as the first-line treatment for T2D. However, an annual failure of metformin therapy has been reported. Newer classes of agents are being developed with novel mechanisms of action: SGLT-2 inhibitors, longer acting GLP-1 agonists, and PPAR $\alpha / \gamma$ dual and pan-agonists. Imeglimin belongs to a new class of drugs "the glimins" developed for the treatment of T2D with an objective to provide a safe and well-tolerated drug with unique pharmacological properties. Imeglimin has a different mechanism of action compared to other oral anti-diabetic compounds. Imeglimin is an innovative compound able to regulate multiple targets, including insulin resistant organs as well as $\beta$-cell failure[106,107].

In patients with T2DM Thiazolidinedione (TZD) therapy improves glycemic control both by strengthening beta cell function and enhancing tissue sensitivity to insulin by acting as peroxisome proliferator-activated receptor (PPAR) gamma agonists in liver and muscle. Insulin resistance and glucose intolerance was reduced with in time delivery of bromocriptine to the central nervous system. Bromocriptine-QR recently was approved by the US Food and Drug Administration (FDA) and is indicated as a supplement to diet and exercise to improve glycemic control in adults with T2DM. BromocriptineQR acts as insulin sensitizer. Current guidelines for T2DM treatment suggested initial therapy with metformin and/or sulfonylurea. Hermes Florez et al. reported that in patients taking TZD with or without another OAA agent, bromocriptine-QR significantly improved glycemic control which persisted over one year of treatment and is not associated with increased risk for peripheral edema or weight gain which is common among those treated with TZDs. Guidelines suggest that glycosylated haemoglobin (HbA1c) should be maintained in diabetes mellitus at $<7 \%$. Such levels of glucose control cannot generally be maintained with oral glucose lowering agents alone and often require use of insulin in addition to, or in place of, oral medications. The efficacy of present antihyperglycaemic agents is limited and most patients do not achieve glycatedhaemoglobin targets[108,109] Two glucagon-like peptide 1 (GLP-1) analogues are approved for use in Canada- liraglutide and exenatide. Similarly, two DPP-4 inhibitors are currently in use in Canada: saxagliptin and sitigliptin. Both GLP-1 analogues and DPP-4 inhibitors stimulate insulin secretion, inhibit glucagon secretion in a glucosedependent manner and have a low risk of hypoglycaemia. Despite having much less tolerability than DPP-4 inhibitors, GLP-1 analogues are exceptional in achieving significant weight loss and lower A1C levels. Recently, a series of phosphonic acid-containing 4-aminobenzimidazoles were reported as adenosine-5' - monophosphate (AMP) mimics, function as inhibitors of fructose1,6-bisphosphatase (FBPase), and demonstrated in vivo glucose-lowering activities in rodent models of T2DM[110,111].

\section{Antiresorptive Drugs}

Antiresorptive drugs include the bisphosphonates and the selective estrogen receptor modulators (SERMs). Several studies have indicated that the anti-resorptive agent alendronate, a potent aminobisphosphonate, has been shown to increase bone mineral density (BMD) at the hip and spine and decrease the incidence of osteoporotic fractures in older women. Patients with diabetes having osteoporosis can tolerate antiresoprtive drugs including the bisphosphonates. Metformin has also been shown to have positive effects on bone turnover by improving metabolic control [112114].

Tomoko Nakagami et al. showed that lipid-lowering treatment of statins reduced cholesterol synthesis but increased cholesterol absorption in patients with T2DM. Ezetimibe may be a useful therapeutic option to prevent micro- and macrovascular complications for dyslipidemia in patients with T2DM. Perioperative use of statins in patients undergoing carotid endarterectomy reduces perioperative mortality, myocardial infarction, and stroke and 2-year mortality. The guidelines recommend changes in lifestyle by diet and exercise as the first line of therapy in the primary prevention of CVD[115-117].

Topical or subconjunctival injection of bevacizumab was found to be effective for inhibiting corneal neovascularization in diabetic patients. Pegaptanib is relatively safer than ranibizumab and bevacizumab. Intravitreal triamcinolone (IVTA) prevents choroidal 
neovascularization, retinal neovascularization and proliferative vitroretinopathy and is a safe way of treatment to proliferative diabetic retinopathy. Combination therapy of topical steroids, NSAIDs (non steroidal anti-inflammatory drugs), and sub-tenon Triamcinolone acetate injection have shown to reduce or prevent macular edema. NSAIDs such as bromfenac and nepafenac are used in the treatment of postoperative inflammation and ocular pain from cataract surgery. Nifedipine therapy is useful for patients with T2DM. It effects on platelet aggregation, lipid metabolism and cardiovascular functions. Nifedipine prevents calcium levels from increasing as much in the cells when stimulated, leading to less muscle contraction. It is reported that Vanadium, a trace element required for human body can reduce the blood glucose values of glycemia animals and has an effect on the treatment of diabetes complications. Vanadium can improve the learning and memory ability. Moreover, due to its relative lower toxicity and high hypoglycemic effect efficiency, organic vanadium may find clinical application in treating neuronal disturbances in the diabetic patients. Normal serum Zinc and good Zinc dietary intake improve osteoblastic function and prevent bone complications[118-120].

\section{Herbal treatment for diabetes}

Bitter Gourd (Momordicacharantia), Bael (Aeglemarmelos), Gurmar Leaves (Gymnemasylvestrae), Fenugreek (Trigonellafoenumgraecum), Turmeric (Curcuma longa), Onion (Allium cepa), Nayantatra (Vincarosa), Neem (Azadirachthaindica), Garlic (Allium sativum), and sagargota (Ceasalpinia crista) are the most useful herbs for diabetic treatment. EA is a polyphenol naturally occurring in berries and nuts has shown many properties such as antioxidant, antimicrobial and antimutagenic agent. Leaf extract of Terminaliaarjuna (Combretaceae), an ayurvedic plant has recently been shown to possess antihyperglycemic activity in streptozotocin-induced diabetic rats. Several plant derived compounds have been shown to activate glucose transport through leaf extract leaf extract AMP Activated Protein Kinase (AMPK) activation Ex: Berberine. Curcumin, a principal curcuminoid of turmeric, salidroside, a bioactive component from Rhodiolarosea and cryptotanshinone, a quinoidditerpene were also reported to have AMPK mediated stimulatory effect on glucose uptake in adipocytes and muscles. The nutraceuticals developed from the soluble and fiber fractions of rice bran control both T1DM and T2DM[121-124].

Physical training or exercise plays a key role in the prevention and treatment of diabetes by improving glucose tolerance and reducing insulin resistance. Regular exercise also reduces diabetes associated complications. The regular practice of the physical exercise has been considered important in the treatment of T2DM. Carla Ribeiro et al. showed that trained group animals have lower values of body weight evolution and body weight gain than sedentary groups. They also found higher blood glucose levels in sedentary alloxan groups. Besides pharmacotherapy, diabetic patients need to focus on the modulation of daily energy intake and expenditure (energy flux) through calorie restriction and brisk exercise to reduce weight (BMI)[125-127].

\section{Alcohol use}

Moderate levels of alcohol help in the treatment of diabetes. Hongmei L et al. study found quadratic curve (U- shaped) relationship between alcohol drinking and diabetes. Alcohol consumption of 26-50 g per day was inversely associated with risk of $\mathrm{T} 2 \mathrm{D}$, compared to non-drinking group, while drinking $>50 \mathrm{~g}$ alcohol per day was not associated with $\mathrm{T} 2 \mathrm{D}$, which appeared to indicate that proper quantities of alcohol consumption may be a protective factor for T2D. Mechanisms of protective effect of proper quantities of alcohol consumption on T2D may be the same as on coronary heart disease[128,129].

\section{Management}

The management of diabetes is so important for diabetics to understand because it helps in controlling the disease and also in preventing complications. Maintenance of normal blood glucose levels suppresses the onset and progression of vascular and neurological complications in T1D patients. Strategies such as diet, exercise and stress management have been strongly recommended and adopted to control T2D. Among those, diet has been seriously considered in controlling type- 2 diabetic hyperglycemia. Consumption of refined foods, polished cereals, and fat have been observed to influence the early onset of impaired glucose tolerance (IGT) which eventually leads to diabetes without any prior warning. Treatment of these cases with "insulin sensitizers" such as metformin appears to be promising in alleviating the associated hyperglycemic condition. The American Diabetic Association (ADA) and the European Association for the study of Diabetes (EASD) published an expert consensus statement on the approach to management of hyperglycemia in individuals with T2D. These guidelines recommend intervention at the time of 
diagnosis with metformin in combination with lifestyle changes (MNT-medical nutriton therapy and exercise). Patients with T2D often have negative self-concepts, feel hopeless and, therefore, become lax about following their regimen. NasrinSamadi et al. study shows that quality of life education can have positive effect on diabetes self concept, and prevent physical and side effects of T2D. T2D can be totally controlled in some cases with diet and exercise. Prevention and treatment methods of obesity will help in the management and treatment of T2DM. Patients need to stop smoking, lose weight if obese. In patients with hypertension blood pressure should be reduced to less than 130/80 mm Hg. Cholesterol levels should be reduced to less than $70 \mathrm{mg} / \mathrm{dL}$. Diabetic patients receiving long-term treatment with steroid eye drops are recommend monitoring their blood glucose levels because topical steroids can affect blood glucose levels. It is recommended to organize educational programs in hospitals for teaching diabetic patients hygienic care, diet, and compliance to physician's instructions regarding nutrition, exercise and medication[130-134].

\section{References}

1. Ajebli M, Eddouks M. The promising role of plant tannins as bioactive antidiabetic agents. Current medicinal chemistry. 2018.

2. Bhat GA, Khan HA, Alhomida AS, Sharma P, Singh R, Paray BA. GLP-I secretion in healthy and diabetic Wistar rats in response to aqueous extract of Momordica charantia. BMC Complement Altern Med. 2018;18(1):162.

3. Hamzah RU, Lawal AR, Madaki FM, Erukainure OL. Methanolic extract of Celosia argentea var. crista leaves modulates glucose homeostasis and abates oxidative hepatic injury in diabetic rats. Comparative clinical pathology. 2018;27(4):106571.

4. Kale OE, Akinpelu OB, Bakare AA, Yusuf FO, Gomba R, Araka DC, et al. Five traditional Nigerian Polyherbal remedies protect against high fructose fed, Streptozotocin-induced type 2 diabetes in male Wistar rats. BMC Complement Altern Med. 2018;18(1):160.

5. Park SB, Park GH, Kim HN, Son HJ, Song HM, Kim HS, et al. Anti-inflammatory effect of the extracts from the branch of Taxillus yadoriki being parasitic in Neolitsea sericea in LPS-stimulated RAW264.7 cells. Biomedicine \& pharmacotherapy = Biomedecine \& pharmacotherapie. 2018;104:1-7.

6. Piovan S, Pavanello A, Peixoto GML, Matiusso CCI, de Moraes AMP, Martins IP, et al. Stevia
Nonsweetener Fraction Displays an Insulinotropic Effect Involving Neurotransmission in Pancreatic Islets. International journal of endocrinology. 2018;2018:3189879.

7. Shah MA, Keach JE, Panichayupakaranant P. Antidiabetic Naphthoquinones and Their Plant Resources in Thailand. Chemical \& pharmaceutical bulletin. 2018;66(5):483-92.

8. Shukla R, Banerjee S, Tripathi YB. Antioxidant and Antiapoptotic effect of aqueous extract of Pueraria tuberosa (Roxb. Ex Willd.) DC. On streptozotocininduced diabetic nephropathy in rats. BMC Complement Altern Med. 2018;18(1):156.

9. Villarruel-Lopez A, Lopez-de la Mora DA, Vazquez-Paulino OD, Puebla-Mora AG, TorresVitela MR, Guerrero-Quiroz LA, et al. Effect of Moringa oleifera consumption on diabetic rats. BMC Complement Altern Med. 2018;18(1):127.

10. Zhao D, Zhao JB. Comparison of Chang Run Tong and Forlaxin Treatment of Constipation in Elderly Diabetic Patients. Journal of alternative and complementary medicine (New York, NY). 2018;24(5):472-80.

11. Mrabti HN, Jaradat N, Fichtali I, Ouedrhiri W, Jodeh S, Ayesh S, et al. Separation, Identification, and Antidiabetic Activity of Catechin Isolated from Arbutus unedo L. Plant Roots. Plants (Basel, Switzerland). 2018;7(2).

12. Njogu SM, Arika WM, Machocho AK, Ngeranwa JJN, Njagi ENM. In Vivo Hypoglycemic Effect of Kigelia africana (Lam): Studies With AlloxanInduced Diabetic Mice. Journal of evidence-based integrative medicine. 2018;23:2515690x18768727.

13. Sasaki M, Nishida N, Shimada M. A Beneficial Role of Rooibos in Diabetes Mellitus: A Systematic Review and Meta-Analysis. Molecules (Basel, Switzerland). 2018;23(4).

14. Kalaycioglu Z, Uzasci S, Dirmenci T, Erim FB. alpha-Glucosidase enzyme inhibitory effects and ursolic and oleanolic acid contents of fourteen Anatolian Salvia species. Journal of pharmaceutical and biomedical analysis. 2018;155:284-7.

15. Kitamura H, Saito N, Fujimoto J, Nakashima KI, Fujikura D. Brazilian propolis ethanol extract and its component kaempferol induce myeloid-derived suppressor cells from macrophages of mice in vivo and in vitro. BMC Complement Altern Med. 2018;18(1):138.

16. Liu Y, Cao Y, Fang S, Wang T, Yin Z, Shang X, et al. Antidiabetic Effect of Cyclocarya paliurus Leaves Depends on the Contents of Antihyperglycemic Flavonoids and Antihyperlipidemic Triterpenoids. Molecules (Basel, Switzerland). 2018;23(5).

17. Moezi L, Arshadi SS, Motazedian T, Seradj SH, Dehghani F. Anti-Diabetic Effects of Amygdalus 
Lycioides Spach in Streptozocin-Induced Diabetic Rats. Iran J Pharm Res. 2018;17(1):353-64.

18. Barzilay JI, Davis BR, Ghosh A, Pressel SL, Rahman M, Einhorn PT, et al. Rapid eGFR change as a determinant of cardiovascular and renal disease outcomes and of mortality in hypertensive adults with and without type 2 diabetes. Journal of diabetes and its complications. 2018.

19. Chen S, Burstrom B, Sparring V, Qian D. Vertical integrated service model: an educational intervention for chronic disease management and its effects in rural China - a study protocol. BMC health services research. 2018;18(1):567.

20. Daniels SI, Chambers JC, Sanchez SS, La Merrill MA, Hubbard AE, Macherone A, et al. Elevated Levels of Organochlorine Pesticides in South Asian Immigrants Are Associated With an Increased Risk of Diabetes. Journal of the Endocrine Society. 2018;2(8):832-41.

21. Granado-Casas M, Alcubierre N, Martin M, Real J, Ramirez-Morros AM, Cuadrado M, et al. Improved adherence to Mediterranean Diet in adults with type 1 diabetes mellitus. European journal of nutrition. 2018.

22. Hossein-Nia B, Khorram S, Rezazadeh H, Safaiyan A, Ghiasi R, Tarighat-Esfanjani A. The Effects of Natural Clinoptilolite and Nano-Sized Clinoptilolite Supplementation on Lipid Profile, Food Intakes and Body Weight in Rats with Streptozotocin-Induced Diabetes. Advanced pharmaceutical bulletin. 2018;8(2):211-6.

23. Kiefer LS, Fabian J, Rospleszcz S, Lorbeer R, Machann J, Storz C, et al. Assessment of the degree of abdominal myosteatosis by magnetic resonance imaging in subjects with diabetes, prediabetes and healthy controls from the general population. European journal of radiology. 2018;105:261-8.

24. Akinpelu OV, Ibrahim F, Waissbluth S, Daniel SJ. Histopathologic changes in the cochlea associated with diabetes mellitus--a review. Otology \& neurotology : official publication of the American Otological Society, American Neurotology Society [and] European Academy of Otology and Neurotology. 2014;35(5):764-74.

25. Alberti KG, Zimmet PZ. Definition, diagnosis and classification of diabetes mellitus and its complications. Part 1: diagnosis and classification of diabetes mellitus provisional report of a WHO consultation. Diabetic medicine : a journal of the British Diabetic Association. 1998;15(7):539-53.

26. Gray N, Picone G, Sloan F, Yashkin A. Relation between BMI and diabetes mellitus and its complications among US older adults. Southern medical journal. 2015;108(1):29-36.

27. Heshmati J, Namazi N. Effects of black seed (Nigella sativa) on metabolic parameters in diabetes mellitus: a systematic review. Complementary therapies in medicine. 2015;23(2):275-82.

28. Joung $\mathrm{KH}$, Jeong JW, $\mathrm{Ku} \mathrm{BJ}$. The association between type 2 diabetes mellitus and women cancer: the epidemiological evidences and putative mechanisms. Biomed Res Int. 2015;2015:920618.

29. Kanguru L, Bezawada N, Hussein J, Bell J. The burden of diabetes mellitus during pregnancy in low- and middle-income countries: a systematic review. Global health action. 2014;7:23987.

30. Kaul K, Tarr JM, Ahmad SI, Kohner EM, Chibber R. Introduction to diabetes mellitus. Advances in experimental medicine and biology. 2012;771:1-11.

31. Kleinberger JW, Pollin TI. Personalized medicine in diabetes mellitus: current opportunities and future prospects. Annals of the New York Academy of Sciences. 2015;1346(1):45-56.

32. Komisarenko Iu I. [Correction by vitamin D3 of disturbed metabolism in patients with diabetes mellitus types 1 and 2]. Ukrainian biochemical journal. 2014;86(1):111-6.

33. Kota SK, Meher LK, Jammula S, Kota SK, Modi KD. Genetics of type 2 diabetes mellitus and other specific types of diabetes; its role in treatment modalities. Diabetes \& metabolic syndrome. 2012;6(1):54-8.

34. Kugler AJ, Fabbio KL, Pham DQ, Nadeau DA. Inhaled technosphere insulin: a novel delivery system and formulation for the treatment of types 1 and 2 diabetes mellitus. Pharmacotherapy. 2015;35(3):298-314.

35. Mihai B, Mihai C, Cijevschi-Prelipcean C, Lacatusu C. Rare types of diabetes mellitus. Revista medicochirurgicala a Societatii de Medici si Naturalisti din Iasi. 2012;116(3):700-7.

36. Pathak M. Diabetes mellitus type 2 and functional foods of plant origin. Recent patents on biotechnology. 2014;8(2):160-4.

37. Roden M. [Diabetes mellitus: definition, classification and diagnosis]. Wiener klinische Wochenschrift. 2016;128 Suppl 2:S37-40.

38. Sanchez-Zamora YI, Rodriguez-Sosa M. The role of MIF in type 1 and type 2 diabetes mellitus. Journal of diabetes research. 2014;2014:804519.

39. Silva MF, Barbosa KG, Pereira JV, Bento PM, Godoy GP, Gomes DQ. Prevalence of oral mucosal lesions among patients with diabetes mellitus types 1 and 2. Anais brasileiros de dermatologia. 2015;90(1):49-53.

40. Tai N, Wong FS, Wen L. The role of gut microbiota in the development of type 1 , type 2 diabetes mellitus and obesity. Reviews in endocrine \& metabolic disorders. 2015;16(1):55-65.

41. Watson P, Preston L, Squires H, Chilcott J, Brennan A. Modelling the economics of type 2 diabetes mellitus prevention: a literature review of methods. 
Applied health economics and health policy. 2014;12(3):239-53.

42. Yun $C$, Xuefeng W. Association between seizures and diabetes mellitus: a comprehensive review of literature. Current diabetes reviews. 2013;9(4):3504.

43. Zaccardi F, Webb DR, Yates T, Davies MJ. Pathophysiology of type 1 and type 2 diabetes mellitus: a 90-year perspective. Postgraduate medical journal. 2016;92(1084):63-9.

44. Hammes HP, Lemmen KD, Bertram B. Diabetic retinopathy and maculopathy. Experimental and clinical endocrinology \& diabetes : official journal, German Society of Endocrinology [and] German Diabetes Association. 2014;122(7):387-90.

45. Kasimov EM, Alieva NI, Mamedzade AN. [Results of YAG-laser vitreolysis in proliferative diabetic retinopathy complicated by vitreous hemorrhage]. Vestnik oftalmologii. 2014;130(4):22-6.

46. Shen J, Hu Y, Liu F, Zeng H, Li L, Zhao J, et al. Vibration perception threshold for sight-threatening retinopathy screening in type 2 diabetic outpatients. Diabetes/metabolism research and reviews. 2013;29(7):525-31.

47. Haritoglou C, Kernt M, Wolf A. [Diabetic maculopathy]. Der Ophthalmologe : Zeitschrift der Deutschen Ophthalmologischen Gesellschaft. 2015;112(10):871-83; quiz 84-6.

48. Douvali M, Chatziralli IP, Theodossiadis PG, Chatzistefanou KI, Giannakaki E, Rouvas AA. Effect of macular ischemia on intravitreal ranibizumab treatment for diabetic macular edema. Ophthalmologica Journal international d'ophtalmologie International journal of ophthalmology Zeitschrift fur Augenheilkunde. 2014;232(3):136-43.

49. Kim J, Kang SW, Shin DH, Kim SJ, Cho GE. Macular ischemia and outcome of vitrectomy for diabetic macular edema. Japanese journal of ophthalmology. 2015;59(5):295-304.

50. Sim DA, Keane PA, Zarranz-Ventura J, Bunce CV, Fruttiger M, Patel PJ, et al. Predictive factors for the progression of diabetic macular ischemia. American journal of ophthalmology. 2013;156(4):684-92.

51. Arevalo JF. Diabetic macular edema: changing treatment paradigms. Current opinion in ophthalmology. 2014;25(6):502-7.

52. Musat $\mathrm{O}$, Cernat $\mathrm{C}$, Labib $\mathrm{M}$, Gheorghe A, Toma $\mathrm{O}$, Zamfir M, et al. DIABETIC MACULAR EDEMA. Romanian journal of ophthalmology. 2015;59(3):133-6.

53. Chang $C$, Zhang $K$, Veluchamy A, Hebert HL, Looker HC, Colhoun HM, et al. A Genome-Wide Association Study Provides New Evidence That CACNA1C Gene is Associated With Diabetic
Cataract. Investigative ophthalmology \& visual science. 2016;57(4):2246-50.

54. Haddad NM, Sun JK, Abujaber S, Schlossman DK, Silva PS. Cataract surgery and its complications in diabetic patients. Seminars in ophthalmology. 2014;29(5-6):329-37.

55. Sai Varsha MK, Raman $T$, Manikandan $R$. Inhibition of diabetic-cataract by vitamin K1 involves modulation of hyperglycemia-induced alterations to lens calcium homeostasis. Experimental eye research. 2014;128:73-82.

56. Apreutesei NA, Chiselita D, Motas OI. Glaucoma evolution in patients with diabetes. Revista medicochirurgicala a Societatii de Medici si Naturalisti din Iasi. 2014;118(3):667-74.

57. Gangwani RA, McGhee SM, Lai JS, Chan CK, Wong D. Detection of Glaucoma and Its Association With Diabetic Retinopathy in a Diabetic Retinopathy Screening Program. Journal of glaucoma. 2016;25(1):101-5.

58. Sharma MD, Farmer JA, Garber A. Type 2 diabetes and cardiovascular risk factors. Current medical research and opinion. 2011;27 Suppl 3:1-5.

59. Sluik D, Beulens JW, Weikert C, van Dieren S, Spijkerman AM, van der AD, et al. Gammaglutamyltransferase, cardiovascular disease and mortality in individuals with diabetes mellitus. Diabetes/metabolism research and reviews. 2012;28(3):284-8.

60. Thomas G, Khunti K, Curcin V, Molokhia M, Millett C, Majeed A, et al. Obesity paradox in people newly diagnosed with type 2 diabetes with and without prior cardiovascular disease. Diabetes, obesity \& metabolism. 2014;16(4):317-25.

61. Tressler MC, Greer N, Rector TS, Ishani A, ErcanFang N. Factors associated with treatment success in veterans with diabetes and hyperlipidemia: a retrospective study. The Diabetes educator. 2013;39(5):664-70.

62. Whitford DL, Al-Anjawi HA, Al-Baharna MM. Impact of clinical inertia on cardiovascular risk factors in patients with diabetes. Primary care diabetes. 2014;8(2):133-8.

63. Chillaron JJ, Flores Le-Roux JA, Benaiges D, Pedro-Botet J. Type 1 diabetes, metabolic syndrome and cardiovascular risk. Metabolism: clinical and experimental. 2014;63(2):181-7.

64. Fujii H, Iwase M, Ohkuma T, Ogata-Kaizu S, Ide H, Kikuchi Y, et al. Impact of dietary fiber intake on glycemic control, cardiovascular risk factors and chronic kidney disease in Japanese patients with type 2 diabetes mellitus: the Fukuoka Diabetes Registry. Nutrition journal. 2013;12:159.

65. Li JW, He SY, Liu P, Luo L, Zhao L, Xiao YB. Association of gestational diabetes mellitus (GDM) with subclinical atherosclerosis: a systemic review 
and meta-analysis. BMC cardiovascular disorders. 2014;14:132.

66. McVeigh GE, Gibson W, Hamilton PK. Cardiovascular risk in the young type 1 diabetes population with a low 10-year, but high lifetime risk of cardiovascular disease. Diabetes, obesity \& metabolism. 2013;15(3):198-203.

67. Mitka M. Study: Exercise may match medication in reducing mortality associated with cardiovascular disease, diabetes. Jama. 2013;310(19):2026-7.

68. Ninomiya $T$. Diabetes mellitus and dementia. Current diabetes reports. 2014;14(5):487.

69. Ohta Y, Tanizawa Y. [Hereditary syndrome associated with diabetes mellitus]. Nihon rinsho Japanese journal of clinical medicine. 2012;70 Suppl 5:205-10.

70. Oyer DS. The science of hypoglycemia in patients with diabetes. Current diabetes reviews. 2013;9(3):195-208.

71. Rawal S, Manning $P$, Katare R. Cardiovascular microRNAs: as modulators and diagnostic biomarkers of diabetic heart disease. Cardiovascular diabetology. 2014;13:44.

72. Santos-Gallego CG, Rosenson RS. Role of HDL in those with diabetes. Current cardiology reports. 2014;16(8):512.

73. Abdella N, Akanji AO, Mojiminiyi OA, Al Assoussi A, Moussa M. Relation of serum total sialic acid concentrations with diabetic complications and cardiovascular risk factors in Kuwaiti Type 2 diabetic patients. Diabetes research and clinical practice. 2000;50(1):65-72.

74. Alexandru N, Badila E, Weiss E, Cochior D, Stepien E, Georgescu A. Vascular complications in diabetes: Microparticles and microparticle associated microRNAs as active players. Biochemical and biophysical research communications. 2016;472(1):1-10.

75. Alwakeel JS, Al-Suwaida A, Isnani AC, Al-Harbi A, Alam A. Concomitant macro and microvascular complications in diabetic nephropathy. Saudi journal of kidney diseases and transplantation : an official publication of the Saudi Center for Organ Transplantation, Saudi Arabia. 2009;20(3):402-9.

76. Basu AK, Pal SK, Banerjee R, Mandal S. A study on micro-albuminuria--an independent risk factor for vasculopathy in diabetes mellitus. Journal of the Indian Medical Association. 2005;103(7):374-5, 82.

77. Camargo EG, Gross JL, Weinert LS, Lavinsky J, Silveiro SP. [Low-dose aspirin in patients with diabete melitus: risks and benefits regarding macro and microvascular complications]. Arquivos brasileiros de endocrinologia e metabologia. 2007;51(3):457-65.

78. De Berardis G, D'Ettorre A, Graziano G, Lucisano G, Pellegrini F, Cammarota S, et al. The burden of hospitalization related to diabetes mellitus: a population-based study. Nutrition, metabolism, and cardiovascular diseases : NMCD. 2012;22(7):60512.

79. Ergul A. Endothelin-1 and diabetic complications: focus on the vasculature. Pharmacological research. 2011;63(6):477-82.

80. Heim A, Feihl F, Waeber B. [ADVANCE: a morbidity mortality study of diabetes and hypertension]. Revue medicale suisse. 2008;4(139):28, 30, 2-3.

81. Henriques J, Vaz-Pereira $S$, Nascimento J, Rosa PC. [Diabetic eye disease]. Acta medica portuguesa. 2015;28(1):107-13.

82. Hirakawa Y, Arima H, Webster R, Zoungas S, Li Q, Harrap S, et al. Risks associated with permanent discontinuation of blood pressure-lowering medications in patients with type 2 diabetes. Journal of hypertension. 2016;34(4):781-7.

83. Jingi AM, Noubiap JJ, Essouma M, Bigna JJ, Nansseu JR, Ellong A, et al. Association of insulin treatment versus oral hypoglycaemic agents with diabetic retinopathy and its severity in type 2 diabetes patients in Cameroon, sub-Saharan Africa. Annals of translational medicine. 2016;4(20):395.

84. Keymel S, Heinen Y, Balzer J, Rassaf T, Kelm M, Lauer $T$, et al. Characterization of macro-and microvascular function and structure in patients with type 2 diabetes mellitus. American journal of cardiovascular disease. 2011;1(1):68-75.

85. Mancia G. Optimal control of blood pressure in patients with diabetes reduces the incidence of macro and microvascular events. Journal of hypertension Supplement : official journal of the International Society of Hypertension. 2007;25(1):S7-12.

86. Menini S, Iacobini C, Ricci C, Blasetti Fantauzzi C, Pugliese G. Protection from diabetes-induced atherosclerosis and renal disease by D-carnosineoctylester: effects of early vs late inhibition of advanced glycation end-products in Apoe-null mice. Diabetologia. 2015;58(4):845-53.

87. Muthuppalaniappan VM, Yaqoob MM. Ethnic/Race Diversity and Diabetic Kidney Disease. Journal of clinical medicine. 2015;4(8):1561-5.

88. Phillips $\mathrm{P}$, Wilson D, Beilby J, Taylor A, Rosenfeld E, Hill W, et al. Diabetes complications and risk factors in an Australian population. How well are they managed? International journal of epidemiology. 1998;27(5):853-9.

89. Reddy VS, Reddy GB. Role of crystallins in diabetic complications. Biochimica et biophysica acta. 2016;1860(1 Pt B):269-77.

90. Shukla K, Dikshit P, Shukla R, Sharma S, Gambhir JK. Hypolipidemic and antioxidant activity of aqueous extract of fruit of Withania coagulans 
(Stocks) Dunal in cholesterol-fed hyperlipidemic rabbit model. Indian journal of experimental biology. 2014;52(9):870-5.

91. Tasic I, Kostic S, Djordjevic D, Lovic D, Lovic M, Miladinovic-Tasic N. 4B.09: DIABETES MELLITUS AND ORGAN DAMAGE, CARDIOVASCULAR DISEASE AND MORTALITY IN HYPERTENSIVE PATIENTS: FOLLOW-UP STUDY. Journal of hypertension. 2015;33 Suppl 1:e55.

92. Virella G, Lopes-Virella MF. The Pathogenic Role of the Adaptive Immune Response to Modified LDL in Diabetes. Frontiers in endocrinology. 2012;3:76.

93. Effect of intensive diabetes treatment on the development and progression of long-term complications in adolescents with insulin-dependent diabetes mellitus: Diabetes Control and Complications Trial. Diabetes Control and Complications Trial Research Group. The Journal of pediatrics. 1994;125(2):177-88.

94. Cochran EK, Valentine V, Samaan KH, Corey IB, Jackson JA. Practice tips and tools for the successful use of U-500 regular human insulin: the diabetes educator is key. The Diabetes educator. 2014;40(2):153-65.

95. Cuddihy RM, Borgman SK. Considerations for diabetes: treatment with insulin pen devices. American journal of therapeutics. 2013;20(6):694702.

96. Danne T, Bangstad HJ, Deeb L, Jarosz-Chobot P, Mungaie L, Saboo B, et al. ISPAD Clinical Practice Consensus Guidelines 2014. Insulin treatment in children and adolescents with diabetes. Pediatric diabetes. 2014;15 Suppl 20:115-34.

97. Depablos-Velasco P, Salguero-Chaves E, MataPoyo J, Derivas-Otero B, Garcia-Sanchez R, Viguera-Ester P. Quality of life and satisfaction with treatment in subjects with type 2 diabetes: results in Spain of the PANORAMA study. Endocrinologia y nutricion : organo de la Sociedad Espanola de Endocrinologia y Nutricion. 2014;61(1):18-26.

98. Edelman S, Pettus J. Challenges associated with insulin therapy in type 2 diabetes mellitus. The American journal of medicine. 2014;127(10 Suppl):S11-6.

99. Ejaz S, Wilson T. Managing type 1 diabetes a journey from starvation to insulin pump. Minerva endocrinologica. 2013;38(2):123-31.

100. Gallwitz B, Westrup D, Schmeisl GW. [Significance of insulin analogues in the treatment of people with type 2 diabetes]. Deutsche medizinische Wochenschrift (1946). 2014;139(43):2199-203.

101. Handorf AM, Sollinger HW, Alam T. Insulin gene therapy for type 1 diabetes mellitus. Experimental and clinical transplantation : official journal of the
Middle East Society for Organ Transplantation. 2015;13 Suppl 1:37-45.

102. Laimer M, Jenni S, Stettler C. [Insulin therapy in type 2 diabetes: a review of "when" over "how" up to "why"]. Praxis. 2015;104(4):181-5.

103. Lovre D, Fonseca V. Benefits of timely basal insulin control in patients with type 2 diabetes. Journal of diabetes and its complications. 2015;29(2):295-301.

104. Passanisi S, Timpanaro T, Lo Presti D, Mammi C, Caruso-Nicoletti M. Treatment of transient neonatal diabetes mellitus: insulin pump or insulin glargine? Our experience. Diabetes technology \& therapeutics. 2014;16(12):880-4.

105. Pitocco D, Rizzi A, Scavone G, Tanese L, Zaccardi F, Manto A, et al. Fields of application of continuous subcutaneous insulin infusion in the treatment of diabetes and implications in the use of rapid-acting insulin analogues. Minerva endocrinologica. 2013;38(3):321-8.

106. Schweyer L, Ziegler O. [Insulin therapy in diabetes treatment]. Revue de l'infirmiere. 2014(203):45-6.

107. Tolle S. [GLP-1 analogues in treatment of type 1 diabetes mellitus]. Deutsche medizinische Wochenschrift (1946). 2014;139(42):2123-6.

108. van Dijk PR, Logtenberg SJ, Gans RO, Bilo HJ, Kleefstra N. Intraperitoneal insulin infusion: treatment option for type 1 diabetes resulting in beneficial endocrine effects beyond glycaemia. Clinical endocrinology. 2014;81(4):488-97.

109. Wong J, Tabet E. The introduction of insulin in type 2 diabetes mellitus. Australian family physician. 2015;44(5):278-83.

110. Yanagisawa $K$, Ashihara $J$, Obara S, Wada N, Takeuchi M, Nishino Y, et al. Switching to multiple daily injection therapy with glulisine improves glycaemic control, vascular damage and treatment satisfaction in basal insulin glargine-injected diabetic patients. Diabetes/metabolism research and reviews. 2014;30(8):693-700.

111. Yeh HC, Brown TT, Maruthur N, Ranasinghe P, Berger Z, Suh YD, et al. Comparative effectiveness and safety of methods of insulin delivery and glucose monitoring for diabetes mellitus: a systematic review and meta-analysis. Annals of internal medicine. 2012;157(5):336-47.

112. Dexue L, Yueyue $Z$. Salmon calcitonin in the treatment of elderly women with type 2 diabetes complicated with osteoporosis. Pakistan journal of pharmaceutical sciences. 2014;27(6 Suppl):2079-81.

113. Diab DL, Watts NB. Bisphosphonates in the treatment of osteoporosis. Endocrinology and metabolism clinics of North America. 2012;41(3):487-506.

114. Drake MT, Clarke BL, Lewiecki EM. The Pathophysiology and Treatment of Osteoporosis. Clinical therapeutics. 2015;37(8):1837-50. 
115. Ferrari S. [Diabetes and osteoporosis]. Revue medicale suisse. 2013;9(390):1256, 8-9.

116. Fraser LA, Papaioannou A, Adachi JD, Ma J, Thabane L. Fractures are increased and bisphosphonate use decreased in individuals with insulin-dependent diabetes: a 10 year cohort study. BMC musculoskeletal disorders. 2014;15:201.

117. Grey A, Bolland M, Fenwick S, Horne A, Gamble G, Drury PL, et al. The skeletal effects of pioglitazone in type 2 diabetes or impaired glucose tolerance: a randomized controlled trial. European journal of endocrinology. 2014;170(2):255-62.

118. Iwamoto J, Sato $Y$, Uzawa $M$, Takeda $T$, Matsumoto $H$. Three-year experience with alendronate treatment in postmenopausal osteoporotic Japanese women with or without type 2 diabetes. Diabetes research and clinical practice. 2011;93(2):166-73.

119. Kajizono M, Sada H, Sugiura Y, Soga Y, Kitamura Y, Matsuoka J, et al. Incidence and Risk Factors of Osteonecrosis of the Jaw in Advanced Cancer Patients after Treatment with Zoledronic Acid or Denosumab: A Retrospective Cohort Study. Biological \& pharmaceutical bulletin. 2015;38(12):1850-5.

120. Lechleitner $M$, Pils $K$, Roller-Wirnsberger $R$, Beubler E, Gasser R, Mrak P, et al. [Diabetes and osteoporosis: pathophysiological interactions and clinical importance for geriatric patients]. Zeitschrift fur Gerontologie und Geriatrie. 2013;46(5):390-7.

121. Hayasaka S, Kodama $T$, Ohira A. Traditional Japanese herbal (kampo) medicines and treatment of ocular diseases: a review. The American journal of Chinese medicine. 2012;40(5):887-904.

122. Kaur R, Afzal M, Kazmi I, Ahamd I, Ahmed Z, Ali $\mathrm{B}$, et al. Polypharmacy (herbal and synthetic drug combination): a novel approach in the treatment of type-2 diabetes and its complications in rats. Journal of natural medicines. 2013;67(3):662-71.

123. Li GQ, Kam A, Wong KH, Zhou X, Omar EA, Alqahtani A, et al. Herbal medicines for the management of diabetes. Advances in experimental medicine and biology. 2012;771:396-413.

124. Lin YJ, Ho TJ, Yeh YC, Cheng CF, Shiao YT, Wang CB, et al. Chinese Herbal Medicine Treatment Improves the Overall Survival Rate of Individuals with Hypertension among Type 2 Diabetes Patients and Modulates In Vitro Smooth Muscle Cell Contractility. PloS one. 2015;10(12):e0145109.

\section{Conflict of Interest: None Source of Support: Nil}

125. Lu HQ, Lu W, Liu J, Yang KJ, Li ZG. Recent Pharmacokinetic Studies in Combination Therapies for Diabetes and Related Vascular Complications. Current vascular pharmacology. 2015;13(4):554-61.

126. Sales DS, Carmona F, de Azevedo BC, TalebContini SH, Bartolomeu AC, Honorato FB, et al. Eugenia punicifolia (Kunth) DC. as an adjuvant treatment for type-2 diabetes mellitus: a noncontrolled, pilot study. Phytotherapy research : PTR. 2014;28(12):1816-21.

127. Smith JD, Clinard VB. Natural products for the management of type 2 diabetes mellitus and comorbid conditions. Journal of the American Pharmacists Association : JAPhA. 2014;54(5):e30418; quiz e19-21.

128. Tag H, Kalita P, Dwivedi $P$, Das AK, Namsa ND. Herbal medicines used in the treatment of diabetes mellitus in Arunachal Himalaya, northeast, India. Journal of ethnopharmacology. 2012;141(3):786-95.

129. Thent $\mathrm{ZC}$, Das $\mathrm{S}$. Involvement of liver in diabetes mellitus: herbal remedies. La Clinica terapeutica. 2014;165(4):223-30.

130. Tiwari P. Recent Trends in Therapeutic Approaches for Diabetes Management: A Comprehensive Update. Journal of diabetes research. 2015;2015:340838.

131. Tong XL, Dong L, Chen L, Zhen Z. Treatment of diabetes using traditional Chinese medicine: past, present and future. The American journal of Chinese medicine. 2012;40(5):877-86.

132. Tong XL, Wu ST, Lian FM, Zhao M, Zhou SP, Chen XY, et al. The safety and effectiveness of TM81, a Chinese herbal medicine, in the treatment of type 2 diabetes: a randomized double-blind placebo-controlled trial. Diabetes, obesity \& metabolism. 2013;15(5):448-54.

133. Wiwanitkit V. Thai ethnopharmacological herbs for diabetes treatment: data collection and informatics tracing for therapeutic property. Diabetes \& metabolic syndrome. 2011;5(2):103-4.

134. Wu W, Zhang LL, Zou J. Research progress on antioxidation effect of traditional Chinese medicine polysaccharides and sports for diabetes prevention and treatment. China journal of Chinese materia medica. 2016;41(14):2591-9. 